\title{
Economic Burden of HIV/AIDS Infection in Iran; a Modelling Approach
}

\section{CURRENT STATUS: POSTED}

Research Square

Hesam Ghiasvand

University of Exeter Medical School

Jebreil Shamseddin

Hormozgan University of Medical Sciences

Akbar Biglarian

University of Social Welfare and Rehabilitation Sciences

abiglarian@gmail.comCorresponding Author

ORCiD: https://orcid.org/0000-0002-9776-7085

DOI:

$10.21203 / \mathrm{rs} .2 .22936 / \mathrm{v} 1$

\section{SUBJECT AREAS}

Health Policy

\section{KEYWORDS}

HIVIAIDS infection, Antiretroviral Therapy, Cost of Illness, Economic Burden, 
Abstract

Background HIV/AIDS infection is a leading cause of mortality and morbidity in developing and poor countries. It may potentially lead to economic burden on health system. Prevalence of HIV/AIDS infection in is a debatable issue among researchers, and as our best knowledge, there is lack in economic evidence in this regard in Iran. The purpose of this study is calculating the economic burden of HIV/AIDS infection in Iran in 2016.

Methods We used a societal perspective to capture the direct and indirect costs attributed to HIV/AIDS infection in until end of 2016. We used a prevalence model based approach to estimate the costs of the infection in Iran. For developing our model, we used the Iran Ministry of Health National Guideline for Managing of the infection of Iran by health and medical practitioners. We analysed the HIV/AIDS Surveillance System in three base case, optimistic and pessimistic approaches as our sensitivity analysis.

Results Total direct costs and indirect costs attributed to the HIV/AIDS infection were 7,946,530 and $1,288,586$ US $\$$ until end of 2016 . In addition, the total cost is $8,785,116$.

Conclusions Direct costs form approximately $85 \%$ of total costs of HIV/AIDS infection in Iran. However, we should consider that these costs are just for about $14.3 \%$ of diagnosed people who are under Antiretroviral Therapy, therefor if the government wants to scale up ART to large proportion of the population, it expectedly will raise.

\section{Full-text}

Due to technical limitations, full-text HTML conversion of this manuscript could not be completed. However, the manuscript can be downloaded and accessed as a PDF. 